\title{
Assessing social care policy through a behavioural lens
}

\author{
Adam $^{\text {Oliver }}{ }^{1}$ \\ Published online: 13 March 2019 \\ (C) The Author(s) 2019
}

\begin{abstract}
Over recent years, a number of behavioural economic-informed policy frameworks have been developed, ranging from soft and hard forms of paternalism, to regulation against negative externalities, the so-called nudge, shove and budge approaches. This article considers these different frameworks as applied to some of the challenges posed by the social care needs of contemporary societies. It is argued that all of the frameworks are worthy of serious consideration in this policy domain, in that they offer food for thought on how financial contributions to pay for social care might be increased, and how the quality of social care provision may be improved given available resources.
\end{abstract}

Keywords Behavioural economics $\cdot$ Budge $\cdot$ Nudge $\cdot$ Paternalism $\cdot$ Shove $\cdot$ Social care

\section{Introduction}

There is a view held by many that social care, like health care, is a special good, the financing and consumption of which ought not to be left entirely to users themselves. If left entirely to the private sphere, social care will be inequitably distributed due to unaffordability and myopia, and yet its appropriate provision is perhaps crucial to the human experience. If delivered well, it can offer mobility, compassion and dignity to the relatively infirm, both young and old. If attempting to offer dignity to all people who have social care needs is not in some sense special, then we can leave social care to those who have the assets to pay for it. Those who cannot afford it would then have to rely on their families, friends or charity to help them, to an even greater extent than they do now. However, assuming that most of us believe that social care is a special good, then, ideally, a public or private insurance system

Adam Oliver

a.j.oliver@1se.ac.uk

1 Department of Social Policy, London School of Economics and Political Science, Houghton Street, London WC2A 2AE, UK 
needs to underpin it, preferably one in which people who are both good and bad risks are willing and able to participate so that premiums are affordable for all.

However, in England the state does not provide financial support for universal social care, and private social care insurance does not exist. There are a number of reasons why insurance companies have not entered this sector: for instance, there is great uncertainty over how long people will live in the future, as well as over changing care and support needs and costs. Lack of supply is not the only issue; there is also a lack of demand for social care insurance, again for multiple possible reasons. For example, there is a general lack of understanding of how the social care system works in England, with many perhaps overestimating the extent to which care is publicly financed and provided when needed. People might often also be reluctant to address an issue, such as infirmity when older, that is unpleasant to think about, and some will prefer to take a risk than to save to pay to cover a distant and unpredictable, if potentially high, cost.

The challenges facing the present and future financing and provision of social care in England and elsewhere are therefore substantial and are expected to be compounded over time by further pressures on social care from an aging population. It appears likely that more care and support will have to be provided in the future, whether from increased public spending, private contributions and/or unpaid care. Key issues, then, are how policy may be designed to counter what many believe to be profound aspects of human irrationality that cause insufficient financial planning for future needs, and to motivate the best possible provision of care from available resources.

This article will endeavour to offer some food for thought on how behavioural economics might be used as an input into the social care policy discourse. My task is to outline some of the behavioural economic phenomena that might be most relevant to policy makers and practitioners in this area, to describe various policy approaches that are informed by behavioural economic findings, and to relate some broad social care policy interventions to these approaches.

\section{Some relevant behavioural economic phenomena}

The behavioural economic phenomena introduced here will be familiar to many readers, but for those new to the topic a brief description may prove helpful. For the purposes of this article it is sufficient to state that behavioural economics is the study of how people make decisions, and to consider a selection of the different ways that people systematically deviate from the assumptions of standard economic theory. These deviations can be viewed as a box of tools for policy makers to use on a case by case basis to attempt to improve the effectiveness of their policy interventions.

Present bias is the observation that people place a heavy weight on the immediate moment, and quickly and greatly discount all future moments. Discounting, even the particular discounting, sometimes called hyperbolic discounting, implied by present bias, is allowed by standard economic theory, but in general exponential discounting with a fixed rate of, say, $3 \%$ or $5 \%$ is used in economic evaluations. Present bias can, however, lead to cases of dynamic inconsistency, a form of preference 
reversal, which makes it difficult to predict what people prefer in the future on the basis of their stated preferences now. For instance, a person may state in the present moment that they prefer to receive $£ 504$ weeks from now over $£ 453$ weeks from now, but when 3 weeks have elapsed the heavy emphasis on the immediate moment might lead them to prefer to take the $£ 45$ rather than wait the additional week for the extra $£ 5$. The immediate moment looms large and heavily affects decisions, which is at least a partial explanation for why people smoke, drink too much, eat too many sweets, take drugs, refrain from exercise and recycling, and save insufficiently for their retirements and potential social care needs.

In standard economic theory it is assumed that the holders of value are final assets-what you end up with is what counts. Behavioural economists, particularly Kahneman and Tversky in their formulations of prospect theory (Kahneman and Tversky 1979; Tversky and Kahneman 1992), have purported to show that the holders of value are often not final assets, but are rather gains and losses around some specific reference point, and that losses matter more than gains, a phenomenon known as loss aversion. Moreover, in prospect theory it is assumed that people are decreasingly sensitive to mounting gains and losses. Emphasising the threat of losses might therefore be a powerful motivator of behaviour change. Importantly, there is no scientific theory on what the reference point will be; it is not necessarily fixed, and is often likely to be the outcome that appears most salient. It can therefore be created and manipulated. Hypothetically, if, for instance, it was widely and aggressively publicised that the average adult saved, say, $£ 10$ per week in a fund for possible social care costs, then this figure might become the collective reference point. Consequently, those saving less than $£ 10$ per week towards this potential need might begin to consider their savings inadequate (i.e. a loss, in some sense), and may thus be particularly motivated to correct their behaviour.

Probability transformation is the observation that people tend to overweight small probabilities and underweight large probabilities, in contrast to the standard economic assumption that people will process mathematical probabilities as given. Loss aversion and probability transformation are the two main modifications that prospect theory makes to the standard economic model. The combination of the decreasing sensitivities to mounting gains and losses around the reference point and the overweighting of small probabilities results in prospect theory predicting a distinct four-way pattern of individual risk attitudes: namely, that people will be risk averse when faced with small probabilities of losses and large probabilities of gains, and risk seeking when faced with small probabilities of gains and large probabilities of losses. Therefore, prospect theory predicts differing risk attitudes within a single individual, a common observation in life that standard economic theory has always struggled to explain. This preeminent theory of behavioural economics predicts that people would be willing to insure themselves against the quite low probability of requiring future social care support, although in the social care context where outcomes are temporally distant, other behavioural economic phenomena, in particular present bias, appears to counteract this expectation.

There are common conceptions that standard models of rational choice theory assume that each individual is motivated by selfish utility maximisation, but there is longstanding work in behavioural economics that appears to show that other 
motivational factors temper this model of selfishness. This is most famously demonstrated by the ultimatum game (e.g. Guth et al. 1982), where some form of reciprocity heuristic that motivates many of us to reward kindness and punish unkindness, at a cost to ourselves, often drives our decisions.

The final modification of standard economic theory considered here is associated with the work of Akerlof and Kranton (2010), who propose that people experience positive utility from working for or being associated with an organisation or a set of institutions with which they identify, and negative utility if they perceive themselves to be outsiders. According to Akerlof and Kranton, our identity defines who we are and will influence our behaviours, because different behavioural norms are associated with different identities. If we take social care providers, or local authorities that are attempting to better incentivise providers, for example, good managers, according to the theory of identity utility, will want workers to be motivated insiders who identify with the goals of the organisation or system, rather than alienated outsiders. If this is achieved, then employees will want to work enthusiastically towards the objectives of the organisation, irrespective of additional personal financial rewards, because they will intrinsically support the organisation's mission. Identity is also related to the concept of reciprocity, in that people may be more willing to behave reciprocally towards those with whom they identify.

Behavioural economics can potentially be used to enrich policy discourse and development across the ideological continuum, and a number of policy frameworks have been developed over recent years to serve these ends.

\section{Behavioural economic-informed policy frameworks}

This section, with reference to social care policy, includes a discussion of how behavioural economics can inform three very different policy frameworks: namely, libertarian paternalism, coercive paternalism and behavioural regulation, otherwise respectively known as nudge, shove and budge approaches.

\subsection{Libertarian paternalism}

The most prominent attempts to apply behavioural economic phenomena to practical policy concerns have accepted the normative welfare economics tradition of utility maximisation. They are principally soft forms of paternalism. These include asymmetric paternalism, developed by Camerer et al. (2003), and libertarian paternalism, formulated by Thaler and Sunstein $(2003,2008)$. These approaches are similar to each other in that they focus upon influencing the behaviour of the consumer and/or citizen, but libertarian paternalism has been much the more influential in policy circles and informs nudge interventions. Thaler and Sunstein use the term libertarian to modify the word paternalism in order to signify that their approach is liberty-preserving: those who wish to choose to continue with the same behaviours, either rationally or irrationally, after being exposed to a nudge intervention must be allowed to do so, and are thus not subject to any regulations or bans. The approach 
is paternalistic in the sense that it aims to motivate behaviour change among those who, on reflection, would have liked to make different choices for themselves. This is key: nudge policies are not focussed upon changing behaviours so as to reduce harms posed to others, but rather to reduce self-imposed self-perceived harms to oneself. Thus, the focus is on reducing negative internalities. Negative internalities occur, according to the libertarian paternalists, because people make errors in their automatic choices, and can be ameliorated by altering the environment- the choice architecture-according to the findings of behavioural economics, so as to bring the instantaneous decisions of those who, on reflection, think that their non-reflective actions are irrational into better alignment with their deliberative preferences.

Libertarian paternalism rules out using significant financial incentives or overt persuasion to change behaviour, but rather, to reiterate, appeals to the cognitive affects and processes that people employ when making automatic decisions. Therefore, although straightforward information campaigns are not, in themselves, nudges, behavioural economics can be used to frame the information in particular ways so that they might have more effect. The Dilnot Report (2011) on the future of social care funding in England proposed that the government should invest in a campaign so as to raise awareness of the personal responsibility borne by future social care costs; when designing such campaigns, it may be worthwhile to note that people unsurprisingly respond more to information that is vivid and salient than if it is abstract, to identifiable rather than statistical lives, and to stories rather than numbers.

Behavioural techniques designed to influence automatic decision making have of course been used by private sector interests for decades as a means to manipulate consumers into buying products. Libertarian paternalists advocate the use of similar tactics by public authorities to enhance welfare rather than increase profits. Insofar that nudges are meant to exploit unconscious decision making processes, they presumably have to be covert. Where they are covert (i.e. where the specific reason for their particular design is hidden), they may compromise liberty, and can legitimately be seen in this regard as strongly statist, particularly when one remembers that they tend to be targeted at internalities.

Thus, three core features of libertarian paternalism, each represented on an axis in Fig. 1, are that it addresses internalities rather than externalities, that it preserves liberty and is therefore antiregulatory, and that its applications are informed by behavioural economics rather than the standard model of rational choice.

Movements up the vertical axis in Fig. 1 indicate that an intervention adopts a more regulatory stance, movements along the horizontal axis indicate the extent to which the intervention is focussed upon addressing externalities rather than internalities, and movements along the axis that is diagonally depicted show the degree to which the intervention is informed by rational choice theory. Nudge policies should cluster around the origin, such as the hypothetical policy box 1 in the Figure, which indicates that the intervention would preserve liberty, be informed by behavioural economics, and be focussed on addressing negative internalities. An example of such an intervention might be to place apples rather than chocolate bars at supermarket checkout counters-in such circumstances a shopper is not required to buy the apples but might, on reflection, prefer to buy an apple rather than a chocolate bar, 


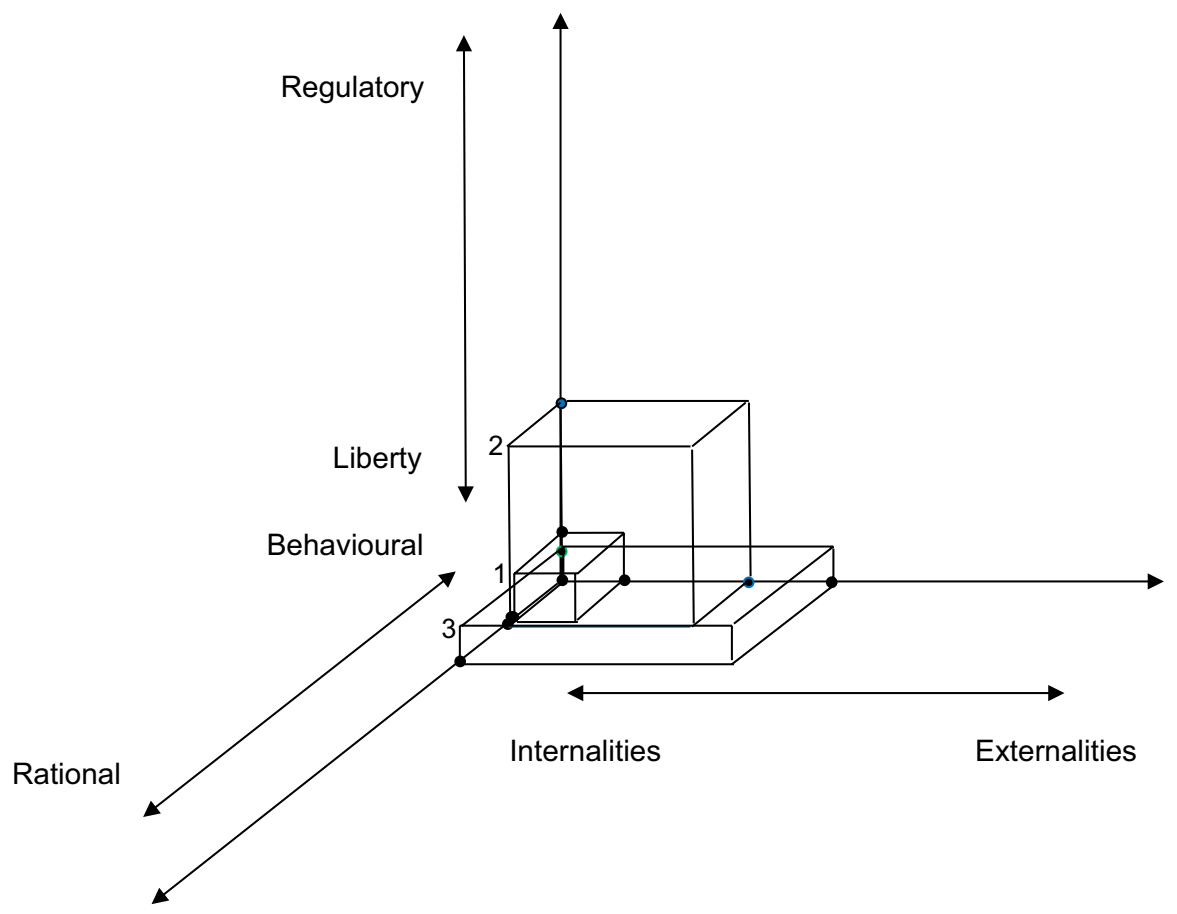

Fig. 1 The libertarian paternalism space

and is more likely to now buy an apple because the presence of the apple near to the checkout has invaded his immediate and automatic decision making mental apparatus. These kinds of ideas might therefore be used to inform to good effect healthier eating and more active lifestyles in care homes. As earlier mentioned, the immediate displeasure experienced when exercising is, due to present bias, a probable reason why many people engage insufficiently in these types of activity; concerted efforts to make exercise more enjoyable for the elderly may often counteract the immediate discomfort, and, if voluntary and if they serve to trigger automatically behaviours that the participants wish to engage in for their own good, would qualify as nudges (e.g. dance classes for older people).

Although potentially having some positive effects, simple manipulations of the demand side that make healthier eating and exercise more accessible and enjoyable, although rarely linked in the popular imagination to behavioural economics, are hardly original, and are unlikely to address more profound social care challenges such as the general reluctance to save towards possible future social care costs. In other areas of policy, changes to what is known as the default position have been shown to have a substantial impact on what people do. This relies on the human behavioural tendency of being very good at not doing anything, such that if the position where people start is altered, it can have a strong effect on where they end up. For example, a far higher percentage of the adult population are registered as organ donors in countries where one has to opt out of being a donor than those where 
one has to opt in, and more people contribute to pension plans where companies automatically enrol their employees compared to companies where employees are required to opt in to a plan (see, for example, Thaler and Sunstein 2008).

It might prove fruitful for social care policy makers to consider this behavioural phenomenon. For instance, might it be possible to default people into a social care tax, subject to a minimum income threshold? People could choose to opt out of the tax if they wish to forgo public financial support for future social care needs except in extreme circumstances, with the tax, in essence, securing entitlement to a predefined social care benefit package. If people are subjected to an opt out system, the loss of coverage rather than the payment of the tax may appear to be the predominant loss, serving to steer them, through feelings of loss aversion, to accept the status quo (psychological intuition suggests that money given up regularly in the form of, say, tax payments or insurance premiums in budgeted purchases may not actually be perceived as losses at all—see Kahneman and Tversky 1984). If the default tax on existing income still proved too off-putting for most people, it might be possible to apply ideas from Thaler and Benartzi's (2004) Save More Tomorrow programme where, in order to increase savings for retirement, people are defaulted into pension schemes whereby they pre-commit to allocating a portion of their future salary increases to retirement savings. Arguably, a default tax for social care would retain autonomy, is informed by behavioural economic theory, and, assuming that those who do not opt out experience improvements in their own lifetime welfare, would satisfy the internality argument in libertarian paternalism, while also reducing at least to some degree the negative externality that current populations impose on future populations through insufficient savings for social care needs. The intervention would at least be nudge-like, and is depicted by box 2 in Fig. 1.

The initial reaction of some people towards the idea of a default tax may not be auspicious; they might contend that it would be politically and individually unacceptable, and ineffective. At least some of these questions are empirical, and it is not the purpose of this article to answer them. Rather, in this section it is to offer a possible solution to the insufficient financing of social care according to the tenets of libertarian paternalism, whereby people must be allowed to avoid the tax, and the tax must be designed such that it is informed by behavioural economics. Other aspects of behavioural economics could potentially be used to strengthen people's acceptance of a voluntary social care tax. For example, since people tend to overweight small probabilities, they may enjoy the immediate thrill of participating in a lottery. It might therefore merit consideration to include a significant lottery prize component into the design of the default tax, creating an affective tax by exploiting probability transformation and present bias. Although perhaps sounding like the ultimate oxymoron, designing an enjoyable tax, or at least attempting to include enjoyable components alongside tax participation, is an idea that perhaps should not be dismissed lightly.

Appealing to notions of reciprocity might also make a new tax more acceptable; that is, if people are informed that although others are principally benefiting from these taxes now, they may benefit from both their own payments and from the payments of others in the future. Reciprocity considerations may also play a key role in whether a Japanese innovation, the fureai kippu (mentioned by the United 
Kingdom's Behavioural Insights Team 2010), can be successfully implemented in the English context. This intervention allows people to voluntarily gain hours, in the form of tickets, for helping elderly people with relatively simple tasks, such as shopping, cleaning and companionship. The tickets are then exchangeable for help for the volunteers themselves when they grow old, or help from other volunteers for elderly relatives who live far away. The fureai kippu, in being voluntary for both the helpers and the helped, preserve liberty, and are in part informed by behavioural economics insofar as the helpers are seemingly responding to reciprocity rather than pure altruism or self-interest, although the latter two motivations may also be present to some degree. The reciprocal nature of the intervention also suggests that both internality and externality considerations are at work-those engaged want to improve the welfare of others and in many cases presumably sacrifice valuable time in order to do so, but nonetheless wish for some ultimate improvements in their own welfare, via a caring utility and future help given to themselves and their loved ones as a consequence of their actions. The fureai kippu thus appear to entail some nudge-like features, and is represented by box 3 in Fig. 1.

Libertarian paternalists are means paternalists: they wish to steer people towards doing what the people themselves judge to be best for their wellbeing, without forcing anyone to do anything. There is a stronger form of paternalism-ends paternalism-that pays less respect to the element of choice. The foremost recent exposition of ends paternalism, Conly's (2013) Against Autonomy, is, like libertarian paternalism, motivated at least in part by behavioural economics.

\subsection{Coercive paternalism}

To reiterate, then, Conly (2013) has the same basic justification as the soft paternalists for wanting to effect behaviour change in that she believes that the behavioural economic affects can cause errors that we should want to correct for the good of those making them. However, by retaining autonomy of choice, she believes that libertarian paternalistic interventions will be insufficiently effective. The libertarian paternalists, for their part, do not tend to believe that all behavioural economicinformed behaviours are necessarily mistakes; for example, Sunstein (2013a), in a review of Conly's book, argues that with respect to present bias, our short-term goals might be a large part of what makes life worth living. Nonetheless, Conly advocates for the explicit regulation of citizens' behaviours where the broadly considered benefits of the regulation are perceived to outweigh the broadly perceived costs. For example, Conly proposes a ban on smoking. Coercive paternalistic measures are sometimes referred to as shoves.

As with libertarian paternalism, the basic tenets of coercive paternalism can be represented in a three dimensional space; this is done in Fig. 2, where the liberty to regulatory axis of Fig. 1 is inverted to depict that a shove is more forceful than a nudge. In Fig. 2, shoves cluster around the origin.

Conly states that legislation should not control most aspects of life, but maintains that it is necessary when people are likely to make decisions that seriously and 


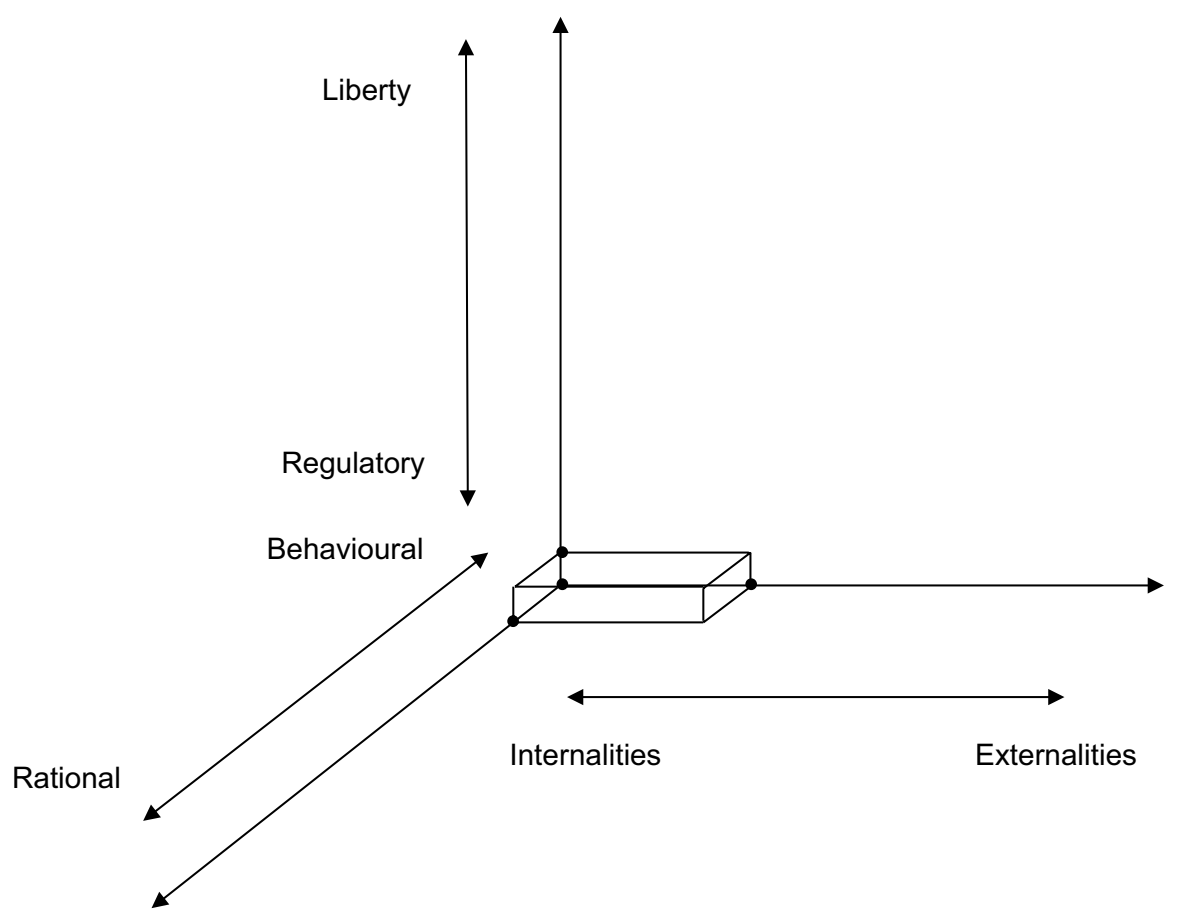

Fig. 2 The coercive paternalism space

irrevocably interfere with their ability to reach their lifetime goals, which she defines as health and financial security. It is clear, then, that she wants to forcibly constrain certain activities, but maintains that some behaviours, such as cigarette addiction and those related to obesity and insufficient retirement savings, are themselves liberty inhibiting if one's lifetime goals are compromised as a consequence.

Conly's arguments are heavily motivated by the desire to counter present bias. If insufficient saving for future social care needs is driven by present bias, an obvious coercive paternalistic measure would be a mandatory social care tax, subject to a minimum income threshold. A mandatory social care tax, like a default tax, would presumably address to some degree negative internalities and negative externalities, and is not, therefore, a purely coercive paternalistic measure, but it is motivated by the presence of present bias and does therefore have definite shove-like qualities. A mandatory tax, unlike a default tax, would have the added benefit of guaranteeing an adequate risk spread, and would not be dissimilar in motivation to social security contributions to qualify for a state pension (or, in the United States, sufficient payroll tax contributions to qualify for Medicare), although the probability of needing social care is lower. The behavioural economic affects could also be used to try to lessen resistance to a new mandatory tax, in ways similar to those earlier suggested in relation to a default tax. The mandatory social care tax is represented by the box in Fig. 2. 
The Dilnot Report (2011) proposed the idea of deferred payments for social care, such that local authorities agree to pay for a person's care in advance if individuals cannot do so without selling their house, on the agreement that the money will be recouped when their house is sold. An extension of this idea is an inheritance tax for social care, where, in line with the Dilnot Report, people agree in advance for their estate after their death to either cover the entire future costs of any social care they require, or that a fixed percentage of their estate be allocated to a social care fund irrespective of whether they themselves need social care in the future. A precommitment of this kind may ameliorate resistance towards paying in the present for distant indeterminate benefits.

Behavioural economics is not confined to the realms of soft and hard paternalism, however. It can also be used to inform where and how to regulate against negative externalities.

\subsection{Regulating against harms}

Regulating against harms to others but not to address internalities, following Mill (1869), is known as the harm principle. Neither libertarian paternalists nor coercive paternalists rule out regulations against harms to others: Sunstein (2013b) advocates for more simple government regulation that is informed by behavioural economics and thus contends that the argument should not be about more or less regulation but rather better regulation, and Conly (2013) believes regulating against harms is non-contentious. Rather than adopt a paternalistic approach, some have argued that it may be more appropriate and effective to use behavioural economics to inform explicit regulation against harms imposed by the supply side. Interventions informed by this approach have been called budges (Oliver 2013).

Like nudges and shoves, the fundamental requirements of budge policy can be depicted in a three dimensional space. Figure 3 replicates Fig. 2, except that the internalities to externalities axis has been inverted. The design of the regulation would not necessarily be informed by behavioural economics in the way that the design of nudges are meant to be informed as such; in budge policy, knowledge of the behavioural economic findings is required in order to detect when private sector interests are using them for their own, sometimes objectionable, ends. That said, the design of the regulation itself can also be informed by behavioural economics so as to attempt to strengthen its effect. Classic budges are regulations against harmful, behavioural economic-informed supply side activities, and will cluster around the origin in Fig. 3.

In relation to social care, budge policy would appear to be most relevant when considering the activities of the formal care providers, the local authority funders and, if a private market were to emerge, private social care insurers. Interestingly, some budge-like suggestions and developments have already been proposed and initiated in England. For instance, The Dilnot Report (2011) called for all information regarding the provision of social care on the national level to be placed on a new single website. When one remembers that people suffer from bounded rationality and rapid cognitive overload, it ought to be kept in mind that for such a website to be 


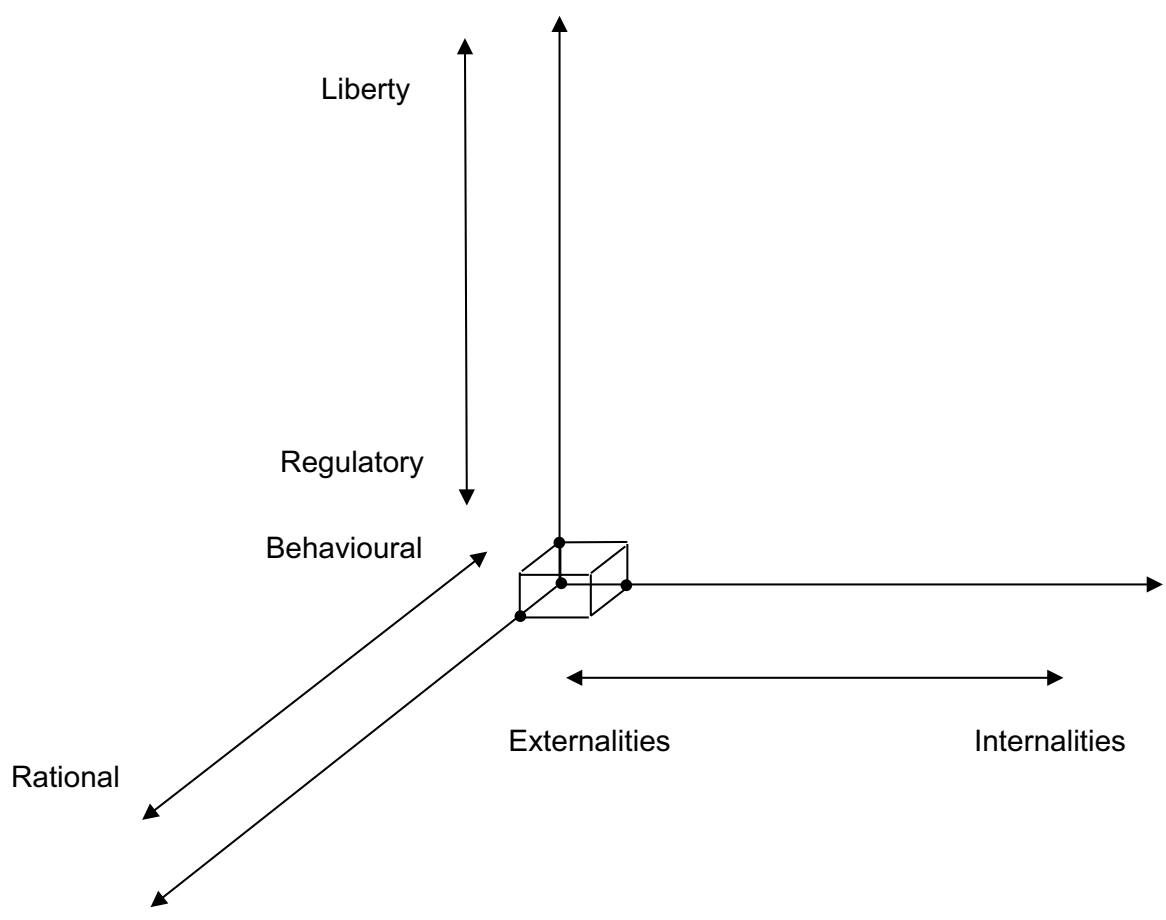

Fig. 3 The budge space

useful, particularly to users and carers who may be harried, old, frail and sometimes confused, access to and the design of the website should be as clear and simple to use as possible. In order to try to motivate better performance from the providers, and indeed the local authorities, the principles of behavioural economics can in this instance be used to inform the design of the budge intervention. For example, the providers could be clearly ranked annually on the website against each other according to their performance, with a salient reference point emphasised to demarcate what may be considered as good or bad relative performance. Alternatively, each provider could be awarded a simple indicator of overall performance, in a manner similar to the star rating system for English National Health Service (NHS) hospitals that operated in the first decade of this century, where zero to three stars were awarded for bad to good performance and where the performance of each hospital was widely, openly disseminated, which partly contributed to a substantial reduction in NHS waiting times (e.g. Oliver 2012). The key, according to the findings of behavioural economics, is to create a clear reference point so that the providers (and users) perceive that performance lower than the reference point is, in some sense, a loss. Thus, due to loss aversion, each provider may be particularly motivated to try to avoid these perceptions being attached to their own organisation.

Creating a league table or metric of performance requires indicators of outcome. Simple indicators appertaining to each provider and local authority could include the visible reporting of what they each charge and cover, which may to some extent 
serve to motivate national standardisation, but clearly it is important that the chosen simple metrics represent genuine potential improvements in service quality. This is one reason why it is important to involve users, carers, providers and funders in the development of the metrics. Another reason to involve service staff is to offer them some ownership over the process, to enable them to identify with the policy intervention. The open publication of relative performance does have the potential to demoralise at least some of the staff who work in the system, and therefore to counter this it is perhaps advisable to attempt to maximise their engagement with the intervention's processes and objectives. Since 2013, the Local Government Association in England has taken some steps towards the public reporting of performance by publishing adult care performance data for all local authorities. However, in order for this intervention to fulfil its potential it is likely that the metrics used need to be simpler and more visible, for users and providers. In general, though, this policy intervention is informed by behavioural economic phenomena, and attempts to ameliorate harms and improve benefits. If local authorities and providers are regulated so that they have to provide the data required, the intervention encapsulates what is meant by a budge, and is represented by the box in Fig. 3 .

\section{Conclusion}

In this article, I have described some of the behavioural economic phenomena and have presented indicative examples of how these may be used in social care through the lens of several policy frameworks. The behavioural affects have complex potential consequences, and though one might prove beneficial, another might prove harmful. For example, creating a clear reference point for good performance might, via notions of reference points and loss aversion, be expected to have desirable effects, but if care is not taken, the same instrument could undermine employees' identity with the organisations within which they work, which is likely to have negative consequences for service users.

Ideological convictions will drive which policy interventions one finds acceptable. If we wish to try to improve the performance of local authorities and care providers but prefer to not interfere in decisions that are principally focused upon internalities, we should perhaps restrict ourselves to budges. If attempts to reduce negative internalities are considered allowable but not enforceable, then soft paternalism offers possibilities; enforceability points towards coercive paternalism. Or we can embrace a mix of these policy frameworks. The beauty of behavioural economics is that it underpins all of them.

Open Access This article is distributed under the terms of the Creative Commons Attribution 4.0 International License (http://creativecommons.org/licenses/by/4.0/), which permits unrestricted use, distribution, and reproduction in any medium, provided you give appropriate credit to the original author(s) and the source, provide a link to the Creative Commons license, and indicate if changes were made. 


\section{References}

Akerlof GA, Kranton RE (2010) Identity economics: how our identities shape our work, wages, and wellbeing. Princeton University Press, Princeton

Behavioural Insights Team (2010) Applying behavioural insight to health. Cabinet Office, London

Camerer C, Issacharoff S, Loewenstein G, O'Donoghue T, Rabin M (2003) Regulation for conservatives: behavioral economics and the case for 'asymmetric paternalism'. Univ Pa Law Rev 1151:1211-1254

Conly S (2013) Against autonomy: justifying coercive paternalism. Cambridge University Press, Cambridge

Dilnot A (2011) Fairer care funding: the report of the commission on funding of care and support. The Stationery Office, London

Guth W, Schmittberger R, Schwarze B (1982) An experimental analysis of ultimatum bargaining. J Econ Behav Organ 3:367-388

Kahneman D, Tversky A (1979) Prospect theory: an analysis of decision under risk. Econometrica 47:263-292

Kahneman D, Tversky A (1984) Choices, values, and frames. Am Psychol 39:341-350

Mill JS (1869) On liberty. Penguin Classics (1982), London

Oliver A (2012) Markets and targets in the english National Health Service: is there a role for behavioral economics? J Health Polit Policy Law 37:647-664

Oliver A (2013) From nudging to budging: using behavioural economics to inform public sector policy. J Soc Policy 42:685-700

Sunstein CR (2013a) It's for your own good!. New York Review of Books, New York City

Sunstein CR (2013b) Simpler: the future of government. Simon and Schuster, New York

Thaler RH, Benartzi S (2004) Save more tomorrow: using behavioral economics to increase employee saving. J Polit Econ 112:s164-s187

Thaler RH, Sunstein CR (2003) Libertarian paternalism. Am Econ Rev 93:175-179

Thaler RH, Sunstein CR (2008) Nudge: improving decisions about health, wealth and happiness. Yale University Press, New Haven

Tversky A, Kahneman D (1992) Advances in prospect theory: cumulative representation of uncertainty. J Rick Uncertain 5:297-323

Publisher's Note Springer Nature remains neutral with regard to jurisdictional claims in published maps and institutional affiliations. 